\title{
Business Models - Nature and Benefits
}

\section{Citation}

Casadesus-Masanell, Ramon, and John Heilbron. "The Business Model: Nature and Benefits." Harvard Business School Working Paper, No. 15-089, May 2015. (Revised June 2015.)

\section{Permanent link}

http://nrs.harvard.edu/urn-3:HUL.InstRepos:15821423

\section{Terms of Use}

This article was downloaded from Harvard University's DASH repository, and is made available under the terms and conditions applicable to Open Access Policy Articles, as set forth at http:// nrs.harvard.edu/urn-3:HUL.InstRepos:dash.current.terms-of-use\#OAP

\section{Share Your Story}

The Harvard community has made this article openly available.

Please share how this access benefits you. Submit a story.

Accessibility 


$$
\text { HAR VAR D B US INESS SCHOOL }
$$

\section{The Business Model: Nature and Benefits}

Ramon Casadesus-Masanell

John Heilbron

Working Paper 15-089 


\title{
The Business Model: Nature and Benefits
}

\author{
Ramon Casadesus-Masanell \\ Harvard Business School \\ John Heilbron \\ Harvard Business School
}

Working Paper 15-089 not be reproduced without permission of the copyright holder. Copies of working papers are available from the author. 


\title{
The Business Model: Nature and Benefits
}

\author{
Ramon Casadesus-Masanell \\ Harvard Business School \\ casadesus@gmail.com \\ John Heilbron \\ Harvard Business School \\ jheilbron@hbs.edu
}

\begin{abstract}
This paper considers the nature of the business model and its strategic relevance to negotiations. We elaborate a substantive definition of the business model as decisions enforced by the authority of the firm; this definition enables the analysis of business models through the analysis of individual firm choices. We situate negotiation outcomes within the strategy literature by considering 'ambivalent value' - value produced by the interaction of partner firms that does not necessarily accrue to any of them. The extent of 'ambivalent value' is unclear, but its persistence, despite changing structural market features, promises to help sustain superior profits in the long run. We conclude with an exploration of some ways in which firms' business models may impact their negotiation outcomes. Several of the proposed pathways work intuitively through the intrinsic characteristics (motivation, personality, etc.) of agents negotiating on behalf of the firm; others operate independently of those characteristics.
\end{abstract}

Keywords: Business Models, Value Capture, Value-Based Business Strategy, Ambivalent Value, 


\section{The Business Model: Nature and Benefits}

\section{Introduction}

When firms participate in transactions, they create and must divide value between themselves. Some value may be assured to each firm - based on how much they would get from their 'next best option' - but the sum of what each is assured does not necessarily equal the total value produced. The leftover value is 'ambivalent value', pulled in two directions at once, and must be split arbitrarily. This essay considers what a business model is, locates the pursuit of 'ambivalent value' in the strategy literature, and proposes a new strategic role for the business model - as a means of negotiating for a portion of that 'ambivalent value'.

We provide a substantive definition of the 'business model', a collection of decisions enforced by the authority of the firm on its employees. There are two aspects of a business model - the internal constitution of the firm and the firm's external alignment - and these are the result of the different degrees of authority a firm has over its employees as opposed to other market actors. A firm may make a variety of decisions regarding either its internal constitution or the types of transactions it facilitates. Conceiving of a business model in this way has a variety of benefits, including the ability to analyze discrete firm choices.

Setting aside this discussion temporarily, we turn our attention to strategy. The careful design of activity systems and the deployment of privileged resources promise to help firms create and sustain competitive advantage in markets that have stable structural features (technological development, consumer tastes, resource barriers, etc.). There are reasons to believe, however, that such structural features change in the long-run, so, to sustain superior returns, firms must find other, more reliable opportunities for capturing value. The dynamic capabilities approach identifies a set of opportunities to capture value that persist despite changing structural market features - opportunities that are due to imperfect competition. The persistence of 'ambivalent value' in markets - despite their structural change - offers firms another set of value capture opportunities.

We conclude by returning to the discussion of business models, and the ways in which firms can manipulate them to negotiate for a bigger cut of the 'ambivalent value'. While scholars have considered business models as being strategically important for their ability to differentiate and create added value, they have not considered their importance in negotiating ambivalent value. We outline a variety of ways in which a firm's business model 
may be a means of doing so: in particular, we develop an approach that incorporates transaction cost considerations into such negotiations, and proposes the strategic value of negotiating with multiple transaction partners.

\section{What is 'ambivalent value'?}

In order to understand ambivalent value, consider an example developed by Brandenburger \& Stuart (1996) to explain the concept. Imagine an economy made up of two suppliers, two firms (A and B), and one consumer. Suppliers provide the raw materials necessary to make a good, firms transform them into a finished product, and consumers benefit from the use of the finished product. Imagine further that each supplier, firm, and consumer provides for, manufactures, and uses at most one unit of the good. Each supplier will sell to at most one firm, and each firm to one consumer; each consumer will buy from at most one firm, and each firm from one supplier. Imagine that the opportunity cost to suppliers of selling to firm A or B is $\$ 1$. In other words, the most they could get by selling their raw materials elsewhere is $\$ 1$. Furthermore, firm A makes a lower quality good which the consumer values at $\$ 10$, while firm B makes a higher quality good which the consumer values at $\$ 15$.

In this example, how many units of good are made? What suppliers, firms, or consumers participate? And how does available value get divided?

There is only one consumer, who can make use of only one unit of good, so only one unit will be manufactured. Only one supplier can be employed, and so the two suppliers will bid down the price at which they offer to sell raw materials in an effort to be the chosen supplier. Of course, they will not bid lower than their opportunity cost, $\$ 1$, so this will be the price at which one of them is chosen to supply raw materials.

Now, if firm A purchases the raw materials for $\$ 1$ and creates a good worth $\$ 10$, they generate $\$ 9$ of value to split between themselves and the consumers. Firm B, on the other hand, would create a good worth $\$ 15$ and have $\$ 14$ of value to split. Firm A and B will bid down their prices in an effort to be chosen by consumers. Of course, firm B has an advantage because its good is valued higher; when it offers a price any lower than $\$ 6$, firm A must offer a price less than $\$ 1$ to offer consumers the same amount of value. Doing so, however, would cause the firm to lose money, and so firm A would choose instead to leave the market.

Because firm B purchases raw materials for $\$ 1$, it would sooner leave the market and net $\$ 0$ than sell goods at less than $\$ 1$ and net a loss. Because firm B must compete on price with firm A to attract the consumer, it must sell its good at less than $\$ 6$. What is unclear is what price in between $\$ 1$ and $\$ 6$ the goods wind up being sold at. If either firm $\mathrm{B}$ or the Chapter 1 in Business Models and Modelling; Volume 33; Advances in Strategic Management editors 
consumer is dissatisfied with the price, then the transaction will fall through - firm B will make nothing and the consumer will be forced to transact with the less desirable firm A. According to Brandenburger \& Stuart, prices are set arbitrarily within this range according to the bargaining ability of each party.

Ambivalent value refers to value falling in this price range of \$1 - \$6: so Firm B and the consumer must split this $\$ 5$ of ambivalent value between themselves. They must agree on how much each party gets - they cannot rely on bargaining and the forces of competition to encourage the other party to cede value. Notice that ambivalent value is only a subset of the total appropriable value - the consumer in the above example, for instance, captures $\$ 9$ in addition to some portion of ambivalent value.

Figure 1 depicts this example and helps explain the nature of 'ambivalent value'. As the solid black arrow shows, Firm B has moved the dashed grey triangle denoting the price of sale, $\mathrm{P}(\mathrm{S})$, from $\$ 15$ to less than $\$ 6$ in order to compete with firm A. As the double-headed dashed grey arrow shows, Firm B and the consumer may locate the dashed grey triangle anywhere between $\$ 1$ and $\$ 6$ - the range of ambivalent value.

\section{Figure 1: The Nature of Ambivalent Value}

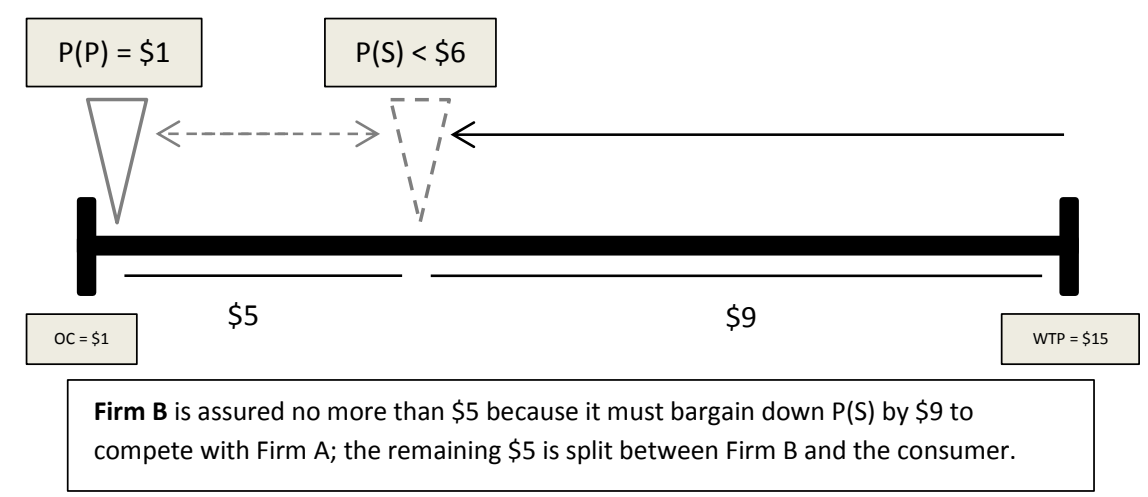

Source Brandenburger and Stuart (1996)

\section{What is a business model?}

'Business' is human activity in a competitive market setting, usually characterized by the exchange of goods and services for money. 'A business' refers to a real collection of people, decisions, resources, buildings, products, values, actions and any other ingredients necessary to conduct and sustain this particular human activity. If we accept these notions, what do we mean by a 'business model'?

Chapter 1 in Business Models and Modelling; Volume 33; Advances in Strategic Management editors 
A firm is an authority structure capable of production and transaction and responsible for creating and capturing value from these business activities. Authority structures rely on sources of power and a source of legitimacy. A firm's power may lie in its ability to fire an employee; a firm can exercise this power without question because it can appeal to a higher voice of authority - the laws of its national state, perhaps. Authority structures are capable of imposing their decisions on the people who are subject to them - they can offer no resistance. The business model of a firm details the decisions that a firm imposes on the agents who work for it. ${ }^{1}$

A firm's business model has two aspects: its internal constitution and its external alignment. The power the firm has over its employees gives it the ability to co-ordinate their productive activity. When interacting with other agents in the free market, a firm does not have this kind of power, and so must buy and sell resources and products by appealing to the self-interest of other parties. In a free market, however, it does retain the authority to determine which such parties it interacts with.

\section{Internal Constitution}

Firms make choices about how to organize their employees' activities so that the manipulation of their material and other resources produces value in the form of a marketable product or service. The activity system describes the actions taken by various firm employees as they acquire the necessary inputs for production, transform them into products or services, and distribute them as goods to other members of the economy. A simple representation of the activity system includes the actions responsible for inbound logistics, operations, outbound logistics, marketing and sales, and service, as well as support activities. These activities create value as each is applied successively to some material good, and when the activities are re-enforcing.

The activity system is a useful way to think about how actions produce value, but it is an oversimplification of the relationship between firms and their employees' activities. A firm does not create value simply by determining the actions of its employees - to do so

\footnotetext{
${ }^{1}$ Note that this is a substantive definition of the business model rather than a functional one. Many scholars (including Amit \& Zott (2001), Baden-Fuller et al. (2008), and Teece (2010)) define the business model in terms of the outcomes it achieves, especially value capture. For some projects, this type of definition is helpful; in this project, we hope to understand the impact of a business model on value capture. If, from the outset, we define the business model as that which captures value, we risk tautology.

Note, further, that this definition conceives of business models as the real but often obscure order that lies beneath the empirical world. By way of contrast, Baden-Fuller \& Morgan (2010) approach the topic of business models by characterizing them as tools of scholarly investigation, constructed 'models of businesses'. Their discussion productively highlights different approaches to modeling businesses.
}

Chapter 1 in Business Models and Modelling; Volume 33; Advances in Strategic Management editors 
precisely in time and space would be a very costly - if not impossible - endeavor. Employees face varying circumstances, and must sometimes deviate from what is expected to actually produce the greatest possible value. Moreover, even if a firm were capable of determining the actions of one employee, strictly coordinating the actions of others would cause significant additional expense. If a business model is the set of determinations enforced by the firm's authority, it is more than just a collection of activities.

Rather than dictate the exact activities of their employees, firms determine procedural norms. On an assembly line, for instance, the firm is not responsible for determining that worker X actually spray-paint a particular car door. Instead, the firm is responsible for the common knowledge that when the door reaches the paint station, it will be spray-painted. Thus, while firms determine procedural norms, workers can adapt their behavior to changes in their environment - if the door doesn't arrive, or if they run out of spray paint. Common knowledge can be shared by several parties, including the other workers on the assembly line, who are better able to coordinate their behaviors with those of worker X, knowing what they are collectively responsible for. Another advantage of procedural norms is that a firm may borrow behavioral norms from other relevant professions (accounting, for instance), and so avoid having to invent them itself.

While they deviate in important ways, procedural norms do correspond in general terms to actions taken by members of the firm. But business models do not consist solely of procedural norms; they also specify bureaucratic structures, which determine employees' rights and responsibilities. A team leader who is responsible for the success or failure of a product launch may be given wide latitude in terms of what they may ask of their subordinates. Notice that by tying responsibility to end results rather than to specific actions, the business model departs significantly from determining the actions of employees in detail, although bureaucratic structures help organize actions. When employees know who is in charge of a particular project, they can approach that person with information relevant to that project's outcome.

Finally, business models can also specify incentive structures - how much an employee stands to gain for their actions. Firms have many incentive structures to choose from - they may pay employees on a wage or salary basis, they may reward specific actions or measurable outcomes, or individual or group performance, and may increase or decrease the levels of remuneration of employees working at different organizational levels. Incentive structures also include details about how employees earn promotion, or move up to different pay scales. Note that, as employees may choose how to spend their time according to Chapter 1 in Business Models and Modelling; Volume 33; Advances in Strategic Management editors C. Baden-Fuller and V. Mangematin; Emerald Press, 2015 
incentives, incentive structures provide a framework that helps, indirectly, to organize activity.

\section{External Alignment}

Firms make choices about which external parties they will negotiate with and which transactions they will participate in. The supply chain describes the parties responsible for bringing a firm good to market, so that consumers may purchase and use it. A simplified representation of the supply chain includes firms that are responsible for sequential activities, organized in the order in which they are performed: for instance, it might include manufacturers, distributors, retailers, and finally individual consumers. Goods flow from manufacturers toward consumers; cash flows in the opposite direction as each party pays for the goods it receives from the previous element of the chain.

While the supply chain is useful as an orienting device, the real world is different from this representation in several important ways - all of which give firms choices regarding the transactions they participate in. A simplified supply chain may depict one firm per niche (e.g. distribution) - but, in fact, many firms may compete to distribute the goods a single firm manufactures. Similarly, a simplified representation may depict each firm as responsible for a single activity (e.g. the firm responsible for distribution is different from the one responsible for retail) - but, in fact, firms may choose to organize themselves so as to offer more than one such activity. Again, a simplified supply chain may not distinguish between a supplier firm's activities (e.g. delivery of print media) and functional roles (e.g. distributor), but a firm's supply chain partners may be involved in multiple activities and roles. Finally, a simplified supply chain may depict only transactions between two parties (e.g. cash for goods), but more than two parties may come together to agree to supply chain transactions.

Both when purchasing raw materials and when selling finished products, a firm has many options of parties with whom it can do business. Sometimes, when a firm does not have explicit control over the distribution of its goods, it will choose its transaction partners implicitly, based on the characteristics of its products. For instance, making smooth rather than crunchy peanut butter may appeal to the tastes of some consumers rather than others. Other times, firms may choose their transaction partners more directly - different people will visit a retail store depending on whether it is located in a beach town or in a sprawling metropolis.

Firms can choose to be involved in a variety of the activities in their supply chains; manufacturing firms may forward integrate into distribution, or firms may merge with others Chapter 1 in Business Models and Modelling; Volume 33; Advances in Strategic Management editors 
to sell related products. Integrating new activities will make firms responsible for new and different transactions. For example, deciding to integrate into distribution means a firm will likely no longer be responsible for transacting with distributors, but rather directly with end consumers, while firms that offer related or competing products now become responsible for selling them if they don't want to lose money on their purchases.

Firms may find that several qualitatively different parties are interested in what they have to offer. Thus, newspapers are organized to mass-distribute information: in the print media supply chain, this capability serves to distribute journalistic output - stories and opinions. However, they have also long distributed advertising information as well: so - while they are responsible for the same activities as in the print supply chain - in the consumer goods supply chain, they serve the function of supplying a valuable resource to advertisers. Because their single set of activities may serve different functions, newspaper publishers may have more options of partners with whom they can transaction business across these two different supply chains to serve readers of both news stories and adverts.

Finally, more than two firms may come together at once to facilitate a transaction. For instance, firms that participate in joint ventures - like South West and Delta - may negotiate prices together from suppliers - such as Boeing. Additionally, rather than purchase goods from producers and sell them on later to consumers in two separate transactions, a distributor may instead act to match the relevant parties, and take a cut of the transaction price, so that one transaction accomplishes the interests of all three parties at once.

\section{Summary}

We have described a business model as a constellation of decisions that are enforced by the authority of the firm. Although business is a chaotic human activity, the procedural norms, bureaucratic structures, and incentive structures a firm enforces can lead its employees to coordinate their activities, producing order. Firms do not have unrestricted authority over their interactions with other market agents; they must appeal to the self-interest of others to facilitate those transactions. However, the external alignment of a firm is still the composition of several decisions that a firm may - to some extent - enforce unilaterally (in that it chooses which transactions it participates in). In this sense, a business model is an act of will rather than simply the product of its environmental circumstances.

There are several benefits to rendering the 'business model' in this way. First, by describing the business model without denying that the firm is an authority structure or that business itself is chaotic human activity, it seems plausible that they are actually essential Chapter 1 in Business Models and Modelling; Volume 33; Advances in Strategic Management editors 
components of the make-up of a particular business. Second, decomposing a business model into a constellation of choices makes it possible to begin analyzing it, piece by piece. Finally, because this definition considers the business model an expression of will, it may prove useful to managers interested in implementing corporate changes.

\section{Strategy and structural change}

Markets that have persistent features (no technological developments, stable consumer preferences, stable resource barriers) offer firms the opportunity to secure value not only from present transactions but also from future transactions of the same kind. Careful design of activity systems and deployment of resources are strategies the literature has proposed to create and then capture value in the long-run. As markets are subject to forces of change over time, without the assurance that structural features will persist, firms may be better off seeking opportunities for value capture that persist in spite of structural change. Dynamic capabilities are the tools managers can use to take advantage of opportunities which arise due to imperfect competition, while business models are tools that they can use to take advantage of opportunities associated with ambivalent value. Both approaches to strategy enable firms to secure superior returns from sequences of dissimilar transactions.

\section{Strategy and stable market structure - Activity systems and Resources}

The field of strategy is concerned with answering the question: How can a firm ensure and sustain superior returns? For business managers, the answer promises profitability: for scholars, the answer is a curiosity, because it stands in contrast to equilibrium, a founding concept in economics.

Consider a handful of firms that have identical cost and revenue structures, competing for consumers on the basis of the price of identical products, and assume that there are unlimited firms 'waiting in the wings' that may join the competitive marketplace at any time. At first, the forces of supply and demand may set a price that is above the costs of any given firm, so that all the firms in the market turn a profit. However, theory suggests that the promise of turning a profit incentivizes more firms to enter and compete, increasing supply and driving down prices until there is no longer any profit to be made. This is the idea of equilibrium - that the profits a firm turns in the short run are the incentives for competition and therefore precisely the reason that the firm will not be able to turn a profit in the long run.

Of course, an important assumption in the equilibrium model is that firms have 
identical cost and revenue structures. In real life, while the costs and revenues of several firms in the same industry may approximate each other, they will certainly not be identical. The entry of new firms may increase supply and drive down prices, but the firm that is capable of offering a quality product at a lower cost will still turn a profit from its sales. The problem facing any strategist embarking on the creative endeavor of improving their firm relative to the competition is that many of their strategic decisions could, presumably, be replicated. The way to sustain superior returns, then, is to find ways of ensuring that competitors cannot imitate one's business operations.

One approach to strategy is to consider the firm as a cluster of activities responsible for bringing a product to market. These 'activity systems' can be designed well or poorly; well-designed systems include activities that are complementary, those that perform better together than they do alone. For instance, Urban Outfitter's high product turnover rates go well with its variable store layout, in that both contribute to a bazaar-like shopping experience (Porter \& Siggelkow, 2008). Of course, complementary decisions could be imitated by competitors, but there are several reasons why decisions that are interdependent tend to obstruct such imitation. Some firm decisions are not observable simply by looking at a firm's manufacturing or store operations, making them hard to imitate. And some may not be worthwhile, or may even be harmful unless made in conjunction with other decisions (Porter \& Siggelkow, 2008; Rivkin, 2000). Designing activity systems that are complex may be a suitable way to fend off the threat of imitation and thereby ensure competitive advantage.

A firm may also be viewed as a bundle of resources over which management has limited control, rather than a series of activities over which management has a great deal of control. At any point in time, different firms will have access to and control over different levels of resources: using them effectively enables firms to ensure superior returns because access barriers will hinder other firms from employing the same kinds of operations - so preventing imitation. For instance, a firm's R\&D team may have established a real rapport over years of working together and developed a knack for dreaming up stylish, new products. In this case, a firm has an advantage in competing on quality and trend-setting in a market, rather than, say, just trying to sell lower quality items cheaply (Wernerfelt, 1984). Other firms may want to compete, but they will not have access to this important cultural resource for success. Unlike Porter, the resource-based view argues that imitation can be deterred not by the obscurity of recipes for success, but by differential access to the ingredients.

The careful design of activity systems and the leveraging of privileged resources are Chapter 1 in Business Models and Modelling; Volume 33; Advances in Strategic Management editors 
solutions to the same managerial problem. Both approaches recognize that, if a competitor is capable of offering the same product in the market, a focal firm will be forced to negotiate prices down until there is no opportunity to turn a profit. We call these 'long-run' approaches to strategy for two reasons. For one, they address threats to profitability that come from imitative competition, a 'long-run' feature in the equilibrium economic model. Second, to sustain superior profits, management must identify and exploit persistent features of the market (e.g. consumer preferences) or of other firms (e.g. resource disparities). In other words, a firm distinguishes itself by achieving repeated success in facilitating the same transactions despite the presence of competition.

\section{Markets and structural change}

Markets' structural features change over the long-run. Government policies may change, and cause tariffs or quotas that operate as barriers to market entry to disappear. The inevitable, though discontinuous, march of technological innovation may erase resource barriers: so, for instance, experience in manufacturing cassettes will have little bearing on the ability to manufacture CDs. Shifting cultural values may change consumer tastes, so a wave of concern about the environment may make consumers more willing to pay for products that are manufactured in responsible ways.

What is more, individual firms' innovative capacities may make structural features that are relevant today irrelevant in the future. A firm with an effectively structured but obscure activity system may not be threatened by the forces of imitation - but over time, other firms may discover new and interesting ways to structure their own activity systems to achieve similar ends more cheaply or effectively, giving them a competitive edge. A firm that has accumulated a valuable resource (such as experience in building motorcycles) may not be threatened by competition from an upstart firm - but, over time, the newcomer may enter related industries and develop the experience needed to overcome the original resource barrier.

To the extent that structural features of a market change over time, firms may be unable to sustain their superior returns simply by conducting similar sequences of transactions (selling the same kind of good to the same kind of customer). Instead, they may have to rely on developing the ability to arrange dissimilar transaction sequences (offering fundamentally different goods to new sets of customers) to achieve superior returns. Of course, the realization that market structures change does not negate the importance of product and resource positioning - rather, it highlights the fact that a firm's strategy must be Chapter 1 in Business Models and Modelling; Volume 33; Advances in Strategic Management editors 
updated from time to time. However, careful consideration of the value capture process identifies two kinds of opportunity to capture value that exist independently of structural market features: imperfect competition and ambivalent value. Because these opportunities do not depend on market structures, approaches to capturing value from them have the advantage of not needing to be updated in line with structural change.

Developments in the literature on value capture distinguish between two fundamentally different processes (Brandenburger \& Stuart, 1996; MacDonald \& Ryall, 2004). On the one hand, firms have 'bargaining power' that assures them some cut of the pie - this has to do with how much bigger they make the pie and how easily they can be replaced. On the other hand, there is a margin of value that goes uncaptured, even after various slices have been allocated to various players. Because creating value is a co-operative process - and everyone has a claim to what's left - firms cannot rely on their 'bargaining power' to secure a share of these 'leftovers': instead, they must exercise their 'bargaining ability' (Grennan, 2013).

Understanding that value is divided on the basis of both 'bargaining power' and 'bargaining ability' yields an important insight for strategy. It distinguishes between two different kinds of short-run profits. There are profits due to a firm's 'bargaining power' - the fact that its goods are necessary for everyone to create value together: traditionally, strategists have divided this category into profits that are due to imperfect competition and those that are caused by a firm's competitive advantage, with the former being 'competed away' over time. ${ }^{2}$ As well as these, there are also profits that flow from a firm's 'bargaining ability' which is based on the fact that a firm is a necessary but insufficient player to produce some of the total value. Of course, if the firm has a competitor that provides exactly the same kind of product for exactly the same price, it will have no opportunity to exercise bargaining ability at all: but any kind of differentiation needs to be capitalized on and translated into profits.

There are also two kinds of opportunities for a firm to capture value which are time sensitive: markets that have not yet become perfectly competitive, and the arbitrary determination of prices in transactions where both parties benefit from transacting specifically with the other. Changing market conditions (new technologies, shifting consumer preferences) do not undermine these opportunities - in fact, the development of new

\footnotetext{
${ }^{2}$ Note that analyzing value capture with the model of identical firms competing on the basis of price does not allow for considerations of 'bargaining ability'. Although not all the literature on strategy explicitly acknowledges its economic foundations, the model of identical firms in a competitive marketplace was introduced because of its relevance to understanding existing strands of the strategy literature. Adopting a different model of value capture, then, is a significant step in understanding the strategic benefits of business models.
}

Chapter 1 in Business Models and Modelling; Volume 33; Advances in Strategic Management editors 
technologies continues to create new markets that are imperfectly competitive. Meanwhile, wherever co-ordination between optimal groups of players creates superior results, there is room for the division of ambivalent value, a form of value that survives changing market conditions. $^{3}$

\section{Strategy and structural change}

Economic equilibrium is a powerful idea, but it may or may not be appropriate to certain industries, especially those in which the innovation and integration of new technologies causes continual change and upheaval. Consider, for instance, the transition from portable cassette players to portable CD players to rudimentary mp3 players to more advanced $\mathrm{mp} 3$ players, like the iPod. When a new technology is introduced, firms that do not take advantage of it become obsolete, while those that integrate the technology successfully enjoy high prices because of the limited supply. Of course, as discussed in the summary of the equilibrium notion above, these profits incentivize other firms to follow their example and integrate the new technology. When innovation in an industry is rapid enough, though, another new technology is likely to be released before the firm ever becomes fully competitive: so, again, the current technology becomes obsolete and the market is once more characterized by a short-term lack of competition. ${ }^{4}$

The problems of firms participating in industries characterized by discontinuous change differ from those in industries marked by equilibrium and perfect competition. Those in the latter face the threat of imitation and the need to provide cost-effective delivery: but imitation is a less significant threat for the former because, once established in the market, the new technology is disrupted by the introduction of even newer technology well before imitative competition drives revenues down towards costs. Instead, such firms are under the constant threat that the products they offer may become irrelevant at any point in time because of the unexpected dawn of a new technology.

To address the problem of relevance, scholars have identified a subset of a firm's resources as its 'dynamic capabilities'. By definition, these are the capabilities that are responsible for helping a firm to adjust to changing economic conditions, such as new

\footnotetext{
${ }^{3}$ It is an open question what portion of profits is due to these two forces on an industry-by-industry basis, and empirical work on this issue has only just begun. Grennan's (2013) estimates indicate that about 79\% of price variation in the market for stents is due to the bargaining ability of various hospitals, as opposed to their demand levels, which are a measure of the bargaining power of the suppliers. While this does not speak directly to the breakdown of profit between the ensured and the negotiated, this is considerable variation.

${ }^{4}$ The fact that the product offerings in each market are substitutes means that it might be tempting to analyze them in the context of the same market. However, the markets must be analyzed separately, as each firm's architecture must be significantly reconfigured to enable it enter any given one.
}

Chapter 1 in Business Models and Modelling; Volume 33; Advances in Strategic Management editors 
technologies and shifting consumer preferences. Some examples include (1) restructuring ownership of physical assets (2) learning new business practices via investment in human resources and (3) understanding changes in the firm's reputation. Even though a firm may never be able to predict or begin planning for the changes that follow from technological advances, cultivating its dynamic capabilities can enable it to detect and respond to changes quickly. The result is that the firm has an edge when new technologies make old ones obsolete; adaptiveness enables firms to capture profits due to imperfect competition in the short-run (Teece, Pisano \& Shuen, 1997). The fact that an industry may contain a series of markets with imperfect competition means that a firm may need to deploy its dynamic capabilities repeatedly to ensure sustained superior returns.

The promise of dynamic capabilities is that they help a firm to adapt to changing market conditions. Firms that make good use of them may enjoy sustained superior returns by facilitating a successful series of different transactions (for example, selling a series of different music playing devices). Firms do not need to worry quite so much about persistent features of the market (like consumer preferences), because discontinuous innovation promises that there will always be markets characterized by imperfect competition for those savvy enough to seek them. Finally, the dynamic capabilities approach is not concerned with imitation, a feature of long-run markets - for all these reasons, we consider it a 'short-run' approach to strategy.

There are other time-sensitive but recurring opportunities to capture value during market changes. The introduction of new technologies gives firms opportunities to take advantage of imperfect competition. Whenever a combination of players is guaranteed more value by working together than the total of what they could make by working separately, some amount of ambivalent value will exist. Changing market structures do not eliminate this ambivalent value, so there are other opportunities to turn a profit by exercising bargaining abilities: as we discuss in the next section, firms may use their business models to exercise these bargaining abilities. For now, we summarize the above discussion in Figure 2, which categorizes the different opportunities available to firms to achieve superior returns. The following different sources of firm profit can be noted:

- Competitive advantage enables a firm to sustain superior returns by facilitating similar transactions in markets with stable structural features in spite of equilibrium pressures. Product and resource positioning help firms establish competitive advantage; 
- Imperfect competition exists in new markets that form as a result of structural change. A firm's dynamic capabilities may help it take advantage of this phenomenon and sustain superior returns by entering markets and facilitating new kinds of transactions;

- Ambivalent value persists in market transactions despite changing structural features of the market. Those aspects of the business model that are relevant for capturing ambivalent value are elaborated later in this essay.

The purpose of this categorization is to specify the source of profit discussed in the remainder of this paper - the exercise of bargaining ability.

\section{Figure 2: Parsing the Sources of Firm Profit}

\begin{tabular}{|c|c|c|c|}
\hline $\begin{array}{l}\text { Relevant } \\
\text { Strategy } \\
\text { Literature }\end{array}$ & $\begin{array}{l}\text { Activity Systems; } \\
\text { RBV }\end{array}$ & $\begin{array}{l}\text { Dynamic } \\
\text { Capabilities }\end{array}$ & $\begin{array}{l}\text { Present } \\
\text { Emphasis }\end{array}$ \\
\hline Source of Profit & $\begin{array}{l}\text { Bargaining } \\
\text { Power: } \\
\text { Competitive } \\
\text { Advantage }\end{array}$ & $\begin{array}{l}\text { Bargaining } \\
\text { Power: Imperfect } \\
\text { Competition }\end{array}$ & Bargaining Ability \\
\hline
\end{tabular}

\section{Business models and strategy}

\section{The strategic value of 'business models'}

There is a difference between identifying the 'business model' as an extant feature of a firm, and so legitimizing it as a category of scientific study on the one hand, and arguing that a firm's 'business model' lies within the strategy field and exhorting managers to pay attention to it as the basis for ensuring superior returns. An historical study, for instance, might describe the conditions under which the retail model emerged and outline reasons for its success - but would not necessarily inform present-day managers about how they should operate a retail model today, or whether or not to adopt one to begin with.

Scholars disagree about the relationship between business models and business strategy. Some distinguish sharply between the two. Magretta (2002), for instance, believes that a business model is a logically sound explanation of how a firm can valorize its activities by appealing to the self-interest of other parties; it is a necessary but insufficient condition of the firm's ability to turn a profit. Strategy, meanwhile, is the distinct activity of a firm differentiating its product offering lest imitation prompt it to bid down prices until it no 
longer makes money. Note that one interpretation of Magretta's argument is that the business model describes the value creation of a firm imagined to exist in isolation: strategy ensures that its value creation is added value rather than value that might be redundant in the context of the market place.

In contrast, other scholars align business models and business strategy much more closely. A business model "depicts the content, structure, and governance of transactions designed so as to create value through the exploitation of business opportunities" (Amit \& Zott, 2001). They draw attention to the fact that firms that facilitate the transactions of goods and services effectively (rather than supplying those goods and services themselves) can make money. Thus, a firm's activities can be designed to create value even when they do not produce a product or service that is valued in and of itself. This means that business model design is synonymous with strategy, because how such firms facilitate transactions will determine how attractive their services are to prospective consumers. ${ }^{5}$ The authors discuss, in particular, the advantages of internet technology for managers who wish to create value, including cheap flows of information and the ability to aggregate disparate consumer traffic. On Ebay, for example, goods are economically aggregated and described, and the community keeps reputational tabs on both sellers and buyers: the way Ebay organizes transactions creates a market from what would otherwise be a dump heap. The authors provide examples like this in which business model innovation has created added value. ${ }^{6}$

Scholars like Magretta (2002) believe that considering business models cannot help managers to capture value because the business model ensures value creation but not necessarily the creation of added value (i.e. something that no one else is offering). On the other hand, others (like Amit \& Zott) believe that consideration and careful design of their business models can help firm managers to capture value, because business models may

\footnotetext{
${ }^{5}$ Amit and Zott (2001) make a valuable contribution by explicating and categorizing economic phenomena that are prevalent in internet businesses but may be less so elsewhere. Considering online firms is an instructive exercise for business strategy, because many of these firms facilitate transactions (even previously impossible transactions) rather than offering a valued good or service themselves. Consequently, their paper draws focus away from a narrow view of value proposition as product characteristics to a broader (and more realistic view) of value proposition as any output a firm has that can be sold to a private individual. The idea that firms should think broadly about their value proposition is not entirely new, to be fair: A good example of this is the idea of in-store customer service to make it easier for customers to find and purchase goods they desire. This is, perhaps, a more arcane way of facilitating 'transaction speed', an advantage of the technological revolution in business that the authors discuss, and, while it is one that requires an hourly wage, it is not a product characteristic per se.

${ }^{6}$ It is at times difficult to tell when the 'value drivers' they discuss are ways of creating value generally and when they are ways of creating added value, specifically. Some value drivers, like direct and indirect network externalities, privilege one firm at the expense of others, meaning that the firm has added value. Other value drivers, like increased transaction speed and decreased bargaining costs, might contribute to e-businesses adding value in comparison to those that do not operate online. Over time, and with the increased incorporation of the internet by businesses, though, this value creation will not distinguish one firm from the next. Thus, although the piece in general strives to demonstrate that business model design is an exercise in strategy, it is sometimes unclear whether the authors are concerned with simple value creation or the creation of added value.
}

Chapter 1 in Business Models and Modelling; Volume 33; Advances in Strategic Management editors 
facilitate transactions in novel ways that do, in fact, end up creating added value. The disagreement between these stances obscures a common emphasis on the importance of added value to value capture. Adding value is necessary in order to capture value, but that is not always all that is required of a firm. Think back to the example crafted by Brandenburger $\&$ Stuart and used at the beginning of this paper to introduce the concept of ambivalent value.

Pointing out the relevance of business models to the division of 'ambivalent value' does not resolve disagreement about whether they are capable of creating added value or not. 'Ambivalent value' rather than 'added value' is the focus of the remainder of the paper. Of course, we are not claiming this is the only reason that business models are strategically important, just one that has gone under-appreciated. Strategy involves decisions that increase the maximum value a firm may be able to capture, decisions that increase the minimum value a firm needs to capture, and decisions that increase the amount of value that it actually captures. In the examples that follow, we presume that firms have the ability to capture more than a minimum amount of value and describe how their decisions about the constitution of their business models enable them to do so.

A firm's business model is relevant to its ability to capture value because it is through its business model that the firm exercises its bargaining ability. Much strategy literature is concerned with the notion of competitive advantage - a firm's ability to turn a profit despite the pressures of competition. Our perspective on the importance of business models does not negate the importance of competitive advantage or answer the puzzle of how to achieve it. It does, however, bring the pursuit of competitive advantage into perspective by reminding managers that focusing solely on that dimension neglects a considerable amount of unspoken-for value that must be actively negotiated. We discuss several examples of situations in which a firm's business model may play an important role in its ability to capture ambivalent value in this way.

\section{Dividing ambivalent value}

As elaborated earlier, business models describe the firm's internal constitution and its relationship to external market actors. With regard to the makeup of the firm, a business model specifies procedural norms, incentive structures that motivate employee activities, and bureaucratic structures outlining their responsibilities. With regard to the firm's relationship to its environment, a business model specifies the firm's boundaries, the activities it integrates and the transactions it chooses to facilitate across those boundaries. A firm's business model also influences the division of ambivalent value between itself and other Chapter 1 in Business Models and Modelling; Volume 33; Advances in Strategic Management editors 
relevant market actors. We illustrate the relevance of a firm's business model to these negotiations with several examples below.

Ambivalent value is very often divided in the context of a transaction, because parties negotiate directly over prices and goods in that setting. We discuss transactions in which Walmart, Ryanair, and Apple engage to demonstrate how internal constitution and external alignment impacts such negotiations. A firm's internal constitution selects, cultivates, and motivates human agents who engage in bargaining on its behalf. As mediated by those agents, the business model determines the success of negotiations for ambivalent value. The choice of firm boundaries allow it - or the agents acting on its behalf - access to credible threats that may be used as bargaining tactics.

There are times when firms do not participate in exchange transactions with each other, but interact in other ways to divide up ambivalent value. For instance, the relationship between Microsoft and Intel was complex even when they were the sole providers of operating systems and microprocessors, respectively, i.e. before there was significant competition in those markets. An important feature of this relationship, however, was that they shared control over the size of the installed base of Windows-Intel PCs. Even though the parties did not transact, this commonly controlled resource and Microsoft's choice of business model enabled Intel to employ 'bargaining tactics' to increase its portion of the ambivalent value they jointly created.

Figure 3 summarizes and categorizes examples (which follow) of how business models impact negotiation outcomes. On the vertical access, we distinguish between two aspects of the business model introduced earlier in this essay: internal constitution and external alignment. Though perhaps somewhat more confusing, the horizontal access is meant only to draw attention to one point: under certain conditions, such as dependence on a commonly controlled resource, firms do not need to exchange goods for money in order to bargain for the ambivalent value they create together.

Figure 3: How business model decisions impact negotiation outcomes

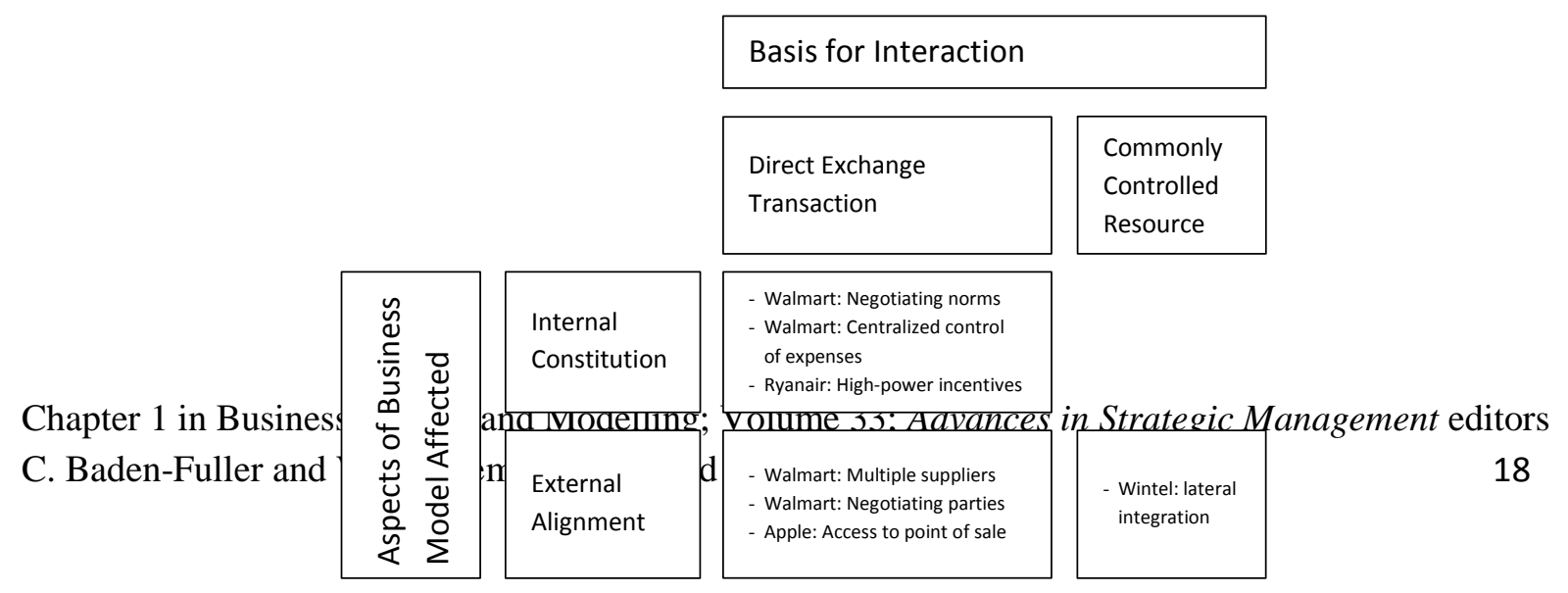




\section{[a] Business models may make employees more effective bargainers}

When one firm sells goods to another, the negotiations that determine the selling price often take place between agents operating on each firm's behalf, so personal characteristics like charisma, effort, or combativeness can play an important role in determining the outcome. Even when a firm's business model does not have a direct impact on these conversations, it may have an indirect impact because of the role that it plays in selecting, grooming, and motivating those agents. As noted earlier, a firm's business model determines the bureaucratic structures, incentive structures, and procedural norms that organize its employees' activities, and this is true of those involved in negotiations just as it is of those in production or administration.

Ryanair is a low-cost airline operating in Europe. It operates a high-power incentive structure, $^{7}$ rewarding employees handsomely and individually for measures of their performance (such as sale of in-flight snacks) and so arguably attracts a certain kind of personality - ambitious, potentially even combative. This is valuable to Ryanair because it relies on negotiating down fees charged by airports and travel agents - combative personalities are likely to be more effective than ameliorative ones at insisting on a greater share of ambivalent value.

Walmart is a low-cost consumer retailer with stores all across the United States. When suppliers come to Walmart's headquarters to negotiate the prices at which they will sell their goods, the retailer employs intimidating procedural norms. Walmart employees only ever call suppliers collect when coordinating such meetings (Ghemawat, Foley \& Bradley, 1994). When supplier representatives arrive, they are not shown to the personal offices of Walmart negotiators, but instead brought to an 'interview room' with nothing more than a table and a few chairs inside. Legend has it that there is a picture of Sam Walton, Walmart's founder, hung in each 'interview room', looking down on the proceedings. Procedural norms that make opposing negotiators uncomfortable can help firms bargain for more ambivalent value.

Ghemawat, Foley \& Bradley (1994) note that Walmart has instituted a bureaucratic structure in which there is highly centralized control of purchases, which can act as a failsafe, ensuring that individuals involved in negotiations that are not going well are able to pull the plug because, at the end of the day, they are simply not authorized to spend so much on buying suppliers' goods. It also means that senior officials - those with the power to redirect

\footnotetext{
${ }^{7}$ In each example, we have italicized the business model decision made by the firm's management.

Chapter 1 in Business Models and Modelling; Volume 33; Advances in Strategic Management editors 
resources - are more closely attuned to successes or failures around the negotiation table, and can make sure their negotiators are properly prepared, both of which mechanisms can help improve the outcomes when dividing ambivalent value.

\section{[b] Business models may empower employees with more effective bargaining tactics}

Decisions about a firm's external alignment may also impact negotiation outcomes. This may seem counter-intuitive, because the firm's internal constitution is responsible for organizing its employees' activities. While the firm's external alignment may not help cultivate negotiators' personal characteristics, it can help make certain tactics available to negotiators or restrict what tactics are available to their opponents.

An important policy guiding Walmart's negotiations is that no one supplier supplies a significant amount of its total purchases - it has decided to populate its boundaries with many transaction partners (rather than a few). Of course, establishing relationships with multiple suppliers requires investment on the part of Walmart in searching, establishing contact, and facilitating transactions.

Let's assume that Walmart can express indifference to transaction costs and commitment to negotiating prices down, and so pays up front to negotiate with multiple suppliers at once. If it does not do so, suppliers will believe that its decisions are, in fact, impacted by transaction cost considerations, and any one supplier that it pays money to transact with will feel 'special' - that is, they will begin to incorporate transaction cost considerations opportunistically when dividing ambivalent value.

What impact does this have on negotiations? This supplier may reasonably, and accurately, assume that other suppliers would feel similarly 'special' if Walmart were to approach them to negotiate similar deals, and knowing this bolsters them in the negotiation process. After all, if negotiations fall through, Walmart may face supply shortages that cost them revenue or damage their reputation, and they would have to pay money to establish contracting relations with another supplier. The next supplier, believing Walmart cares about transaction costs, will incorporate these into its negotiating stance, leaving Walmart in a worse position than it was before.

The result is a 'race-to-the-top', in which each supplier tacks on not only the transaction costs of negotiation failure but also of negotiation failure with future suppliers, knowing that future suppliers will behave in a similarly aggressive manner. For instance, Supplier A knows that if Walmart fails to make a deal, it will have to pay the cost of negotiation failure, only to be met by Supplier B, resolutely bargaining for the cost of a second failed negotiation. Notice that Walmart is no worse off paying twice the cost of failed Chapter 1 in Business Models and Modelling; Volume 33; Advances in Strategic Management editors 
negotiation to A than it is suffering the cost once and paying it once to B. Supplier A is therefore confident that it can negotiate for twice the cost of failed negotiation. The process could, presumably, continue indefinitely, but let's assume it stops there.

Why doesn't Supplier A consider the possibility that Walmart might make arrangements to contract with many suppliers simultaneously? After all, the purpose of this exercise is to demonstrate the strategic value of Walmart's decision that enhances its ability to capture value. Supplier A may consider this possibility, but because it does so as a counterfactual, it does not consider how its confidence (i.e. willingness to bargain aggressively) would change were Walmart to actually commit to this investment. It believes reasonably (by assumption based on present circumstances) but inaccurately - that Walmart will face stout resistance from the other supplier. Forced to part with as much value as it would had it bargained with just one supplier, it would be worse off having spent money negotiating with more than one.

The fact of the matter is that, by establishing contact with multiple suppliers, Walmart changes conditions considerably. Having communicated its indifference to transaction costs in bargaining with suppliers as common knowledge, suppliers no longer feel 'special' when Walmart approaches them. They believe that Walmart will not hesitate to spend money to find another transaction partner that is willing to part with more of the ambivalent value. And - reasonably and accurately - they believe that other firms feel the same way.

The result of the new configuration is a 'race-to-the-bottom', in which each supplier tries to determine the least amount of ambivalent value that any other supplier would be willing to accept in order to close the deal. In theory, this process could weaken suppliers' demands until they have sacrificed all the ambivalent value, although it seems reasonable to assume that there is some minimum amount of face-saving value that suppliers might demand out of self-respect or a sense of fairness.

Whatever the ultimate outcome of the 'race-to-the-bottom', the insight is that Walmart's decision to contract with multiple suppliers is strategically motivated. Although it costs Walmart more to do so, it changes other firms' perceptions of it, and encourages them to sacrifice more ambivalent value, with the result that, in the end, the 'race-to-the-bottom' improves the outcome for Walmart. To this end, consider the simple numerical example below.

Let's assume that Walmart has three possible suppliers willing to supply its stores with a particular product. It may contract with any or all of them, but must pay $\$ 1$ up front to contract with each and loses $\$ 1$ in each case if negotiations fall through. The total amount of Chapter 1 in Business Models and Modelling; Volume 33; Advances in Strategic Management editors 
value created by the transactions is unknown, but $\$ 10$-worth of ambivalent value is created when totaling the outcomes from the transactions performed with each supplier.

When Walmart anticipates using a single supplier and invests only enough to transact with it, the supplier bargains aggressively and demands $\$ 4$. (As Walmart will lose $\$ 1$ if the transaction fails, and must pay another $\$ 1$ to restart negotiations with another supplier, a failed transaction will cost Walmart $\$ 2$ - so this $\$ 4$ represents twice the cost of negotiation failure to Walmart.) Sharing the common knowledge that Walmart cares about maximizing the value it captures, the supplier (accurately) believes that Walmart would do no better by breaking off negotiations and pursuing another firm (at which point it will have spent $\$ 3$ on transaction costs and be faced with another demand for $\$ 4$ ). But, failing to recognize the context of this common knowledge, it inaccurately believes that Walmart would also do no better by contracting with multiple suppliers at once (at which point it will have spent $\$ 3$ on the costs of three separate transactions and, as far as Supplier A knows, face a total demand for ambivalent value of $\$ 4)$.

By investing \$3 up front, Walmart changes the contour of the negotiations. When all firms share the common knowledge that Walmart is willing to incur transaction costs to find the cheapest purchase price for goods, they are less aggressive when bargaining. Firms consider themselves to be replaceable, and so allow Walmart to make an aggressive 'take-itor-leave-it' offer - nine-tenths of the ambivalent value with each supplier. Thus the suppliers - collectively - earn only $\$ 1$ and Walmart takes home a total of \$9. After accounting for the $\$ 3$ spent arranging the negotiations, it pockets $\$ 6$, an improved outcome.

Figure 4 summarizes the outcomes of negotiation for ambivalent value between Walmart and its vendors. The fully saturated patterned bars denote the value that accrues to Walmart and its vendors, and the value that is lost as transaction costs when Walmart establishes relationships with only Vendor A or with multiple vendors. Although more value is lost as transaction costs in the latter scenario, Walmart actually ends up capturing more of the ambivalent value. The unsaturated patterned bars denote the reasonable, but not fully informed, expectations of Vendor A, which explain why it continues to negotiate aggressively when Walmart has not yet established a relationship with other vendors. Vendor A assumes (understandably, but wrongly) that Walmart will be worse off whether it moves on to a second vendor or widens its search to multiple vendors. 
Figure 4: Outcomes of negotiations for ambivalent value between Walmart and its suppliers

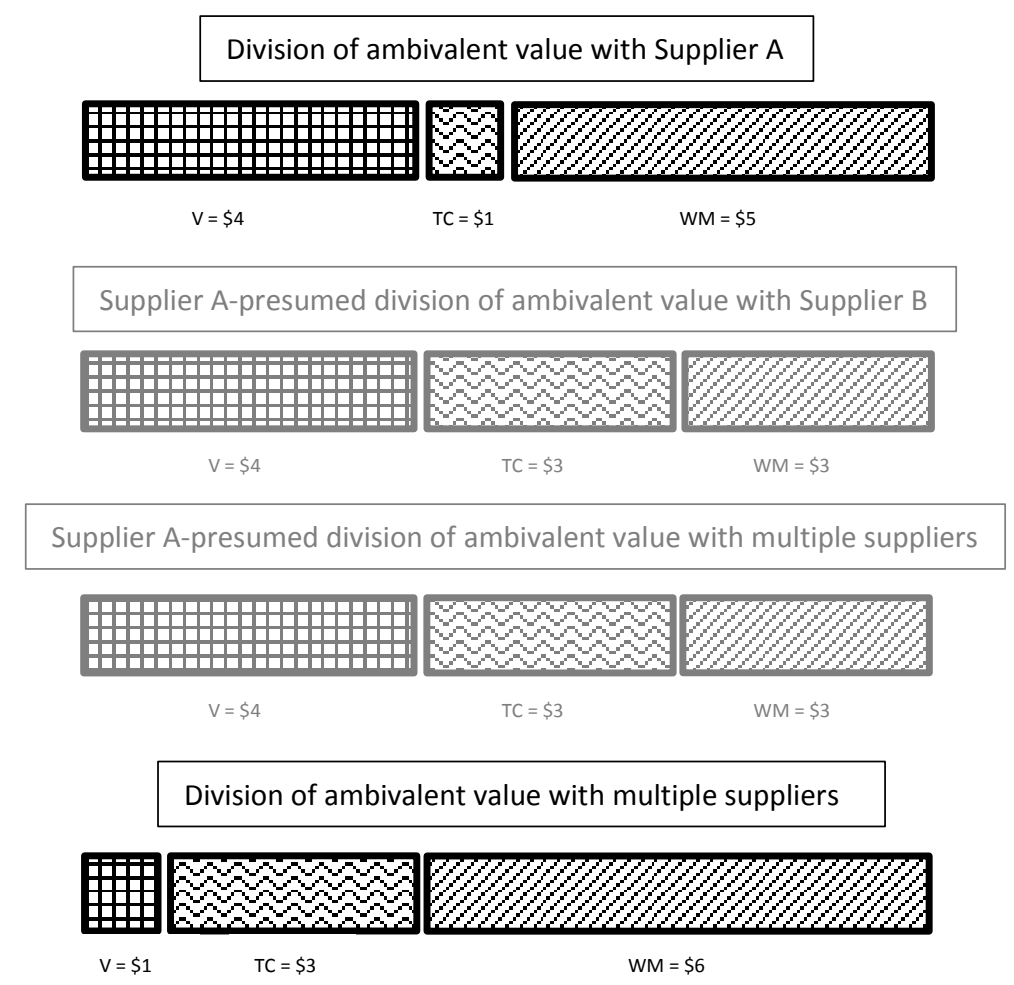

Although Walmart used to meet with both suppliers and manufacturers when negotiating sale prices, they later succeeded in eliminating manufacturers' representatives from these negotiations (Ghemawat, Foley \& Bradley, 1994), a decision which populated its boundaries with fewer oppositional parties at the point of transaction. After all, although suppliers and manufacturers occupy distinct niches in the supply chain, they split between them whatever ambivalent value Walmart does not accrue. As a result, they have an interest in co-operating in raising prices for Walmart. Eliminating manufacturers from the negotiation table prevents suppliers from using tactics that rely on co-ordination with the two parties.

In another example of how firms manipulate markets to appropriate larger shares of ambivalent value, Apple has decided to forward integrate, to facilitate the sale of its technology so that its boundaries align directly with those of its consumers rather than of its distributors (Ryall, 2013).Negotiating with distributors is very different from negotiating with customers. Customers may not think to haggle, and may accept the price of an iPod as posted online or in an Apple store. Haggling may be too costly for customers, who would only stand to gain the ambivalent value associated with only one unit of good. This allows Apple to 
make a more credible 'take-it-or-leave-it' price offer, and so accrue more value from the transaction. ${ }^{8}$ Notice that no Apple employee is actually responsible for negotiating the price, demonstrating that the effectiveness of the firm's business model here is due to the tactics it enables, rather than the employee actions that it fosters.

\section{[c] Business models may condition a firm's dependence on jointly controlled resources}

When ambivalent value must be divided by parties that are adjacent in the supply chain, they can do so by negotiating sale prices. However, ambivalent value may be created by parties who are not immediately up or downstream of each other in the supply chain. By definition, complementary products are worth more to consumers when offered together than the total of each individual one. A computer is composed of a microprocessor and an operating system both virtually worthless to consumers separately but immensely valuable together. However, firms selling complements generally occupy positions that are laterally adjacent on the supply chain, and so often have no reason to transact between themselves.

Early in the market for PCs, Windows and Intel dominated the respective operating system and microprocessor markets. Microsoft was laterally integrated, though, so that it organized the production and sale of applications that users could install onto a particular Windows operating system. Thus, Microsoft was responsible for selling two related types of goods to the same set of consumers. Microsoft's choice of business model made it dependent on the size of the Windows-Intel installed base - if users did not buy a Windows-Intel computer, they would certainly not buy Windows applications to install on it (CasadesusMasanell \& Yoffie, 2007). Microsoft had partial control over the size of this installed base: by lowering the price of its operating system, it could increase its size. However, Intel also had control over the size of that base, and could reduce it by increasing the price of the microprocessor. Joint control over this resource necessitated that the two firms interact. Intel increased the price of its microprocessors beyond what might have been profit maximizing had Microsoft not taken responsibility for the sale of applications. To preserve the size of the installed PC base, and maximize revenue from sales of its applications, Microsoft sold Windows at a lower price: thus Intel captured a greater amount of value from the sale of Windows-Intel PCs because of Microsoft's choice of business model.

\footnotetext{
${ }^{8}$ Notice the similarities between this and the Walmart example. Apple presumably has the choice of investing less money and bargaining with one of a few distributors or investing more money and bargaining one-on-one with many, many individual customers. Despite the structural similarity of the problem, the boundaries of the firm in question are quite different when considered in supply chain terms. Apple's decision is a question of forward integration, i.e. choosing to oversee transactions further down the supply chain, whereas Walmart's is a question of supply source, i.e. choosing which transactions to oversee in order to secure supply, without considering integrating new activities.
}

Chapter 1 in Business Models and Modelling; Volume 33; Advances in Strategic Management editors 


\section{Conclusions}

We have proposed a concept of the 'business model' as a set of decisions enforced by the authority of the firm, and elaborated several of these decisions. We considered several choices a firm could make to its benefit when negotiating with external partners for a share of the 'ambivalent value' created. Such opportunities are important for managers interested in sustaining superior returns because they persist despite changes in market structures. This work is important for managers who want to think precisely about the organizational determinants of negotiation outcomes. In future work, we hope to consider the merits of our definition of the business model, and address when and how it plays a role in competitive advantage, an enduring concern in the field of strategy.

\section{Acknowledgements}

We thank Charles Baden-Fuller and Vincent Mangematin for the invitation to contribute to this Special Issue and for their feedback on our early drafts. We also thank Jon Morgan of Paraphrase for editing later drafts.

\section{References}

Amit R. \& Zott C. (2001). Value Creation in E-business. Strategic Management Journal 22(6-7): 493-520. doi:10.1002/smj.187.

Baden-Fuller C., MacMillan I.C., Demil B., \& Lecocq, X. (2008). Call for Papers for Long Range Planning Special Issue on Business Models.

Baden-Fuller C. \& Morgan M.S. (2010). Business Models as Models. Long Range Planning 43(2-3): 156-71. doi:10.1016/j.lrp.2010.02.005.

Brandenburger A.M. \& Stuart, H.W. (1996). Value-based business strategy. Journal of economics \& management strategy 5(1): 5-24.

Casadesus-Masanell R. \& Ricart J.E. (2010). From Strategy to Business Models and onto Tactics. Long Range Planning 43(2-3): 195-215. doi:10.1016/j.lrp.2010.01.004.

Casadesus-Masanell R. \& Yoffie D.B. (2007). Wintel: Cooperation and Conflict. Management Science 53(4): 584-98.

Ghemawat P., Foley S., \& Bradley S.P. (1994). Wal-Mart Stores, Inc. Harvard Business School Cases.

Grennan, M. (2013). Price Discrimination and Bargaining: Empirical Evidence from Medical Devices. American Economic Review 103(1): 145-77. doi:10.1257/aer.103.1.145.

MacDonald G. \& Ryall M.D. (2004). How Do Value Creation and Competition Determine Whether a Firm Appropriates Value? Management Science 50(10): 1319-33. doi:10.1287/mnsc.1030.0152.

Magretta, J. (2002). Why Business Models Matter (The Difference between Business Models and

Chapter 1 in Business Models and Modelling; Volume 33; Advances in Strategic Management editors

C. Baden-Fuller and V. Mangematin; Emerald Press, 2015 
Strategy). Harvard Business Review 80(5): 86.

Porter M.E. (1996). What Is Strategy?. Harvard Business Review 74(6): 61-78.

Porter M. \& Siggelkow N. (2008). Contextuality Within Activity Systems and Sustainability of Competitive Advantage. Academy of Management Perspectives 22(2): 34-56. doi:10.5465/AMP.2008.32739758.

Rivkin J.W. (2000). Imitation of Complex Strategies. Management Science 46(6): 824-44. doi:10.1287/mnsc.46.6.824.11940.

Ryall M.D. (2013). The new dynamics of competition : an emerging science for modeling strategic moves. Harvard Business Review 91(6): 80-87.

Sterman J. \& Sterman J.D. (2000). Business Dynamics: Systems Thinking and Modeling for a Complex World with CD-ROM. Boston: McGraw-Hill/Irwin, 2000.

Teece D.J. Business Models, Business Strategy and Innovation. (2010). Long Range Planning 43(23): 172-94. doi:10.1016/j.lrp.2009.07.003.

Teece D.J., Pisano G. \& Shuen A. (1997). Dynamic Capabilities and Strategic Management. Strategic Management Journal 18(7): 509-33.

Wernerfelt B. (1984). A Resource-Based View of the Firm. Strategic Management Journal 5(2): 17180.

\section{Biographies:}

Ramon Casadesus-Masanell is the Herman C. Krannert Professor of Business Administration at Harvard Business School. He received his Ph.D. in Managerial Economics and Strategy from the Kellogg Graduate School of Management at Northwestern University. He specializes in management strategy, managerial economics and industrial organization and studies the strategic interactions between organizations operating different business models. He has published in Management Science, the Journal of Economics \& Management Strategy, the Academy of Management Review, the Journal of Law \& Economics and the Journal of Economic Theory, among others. He teaches courses for MBA candidates, Ph.D. candidates, and on Executive Education programs. e-mail: casadesus@gmail.com

John Heilbron is a research associate at Harvard Business School. He received his BA in Social Studies from Harvard College, where he studied American religion. His research interests include business models, transaction cost economics, and the history of industrial organization. . e-mail: jheilbron@hbs.edu

Chapter 1 in Business Models and Modelling; Volume 33; Advances in Strategic Management editors 